\title{
Management of recurrent apthous stomatitis-current trends \& perspective
}

\author{
Akhilanand Chaurasia ${ }^{1, *}$, Akansha Vatsa ${ }^{2}$ \\ ${ }^{1}$ Assistant Professor, ${ }^{2}$ Resident, Dept. of Oral Medicine \& Radiology, Faculty of Dental Sciences, King George’s Medical \\ University, Lucknow, Uttar Pradesh, India \\ *Corresponding Author: \\ Email: chaurasiaakhilanand49@gmail.com
}

\begin{abstract}
Recurring oral ulcers are among most common oral disease encountered by oral physicians in day to day practice.Recurrent apthous stomatitis (RAS) is a common disorder characterized by recurring ulcers confined to the oral mucosa with no other signs of systemic diseases. It affects approximately $20 \%$ of general population. Clinically it is classified as minor ulcers, major ulcers and herpetiform ulcers. This article insights the current trends in management of this commonly occurring disease.
\end{abstract}

Keywords: Recurrent Aphthous Stomatitis, Oral ulcers, Etanercept, Autoimmune diseases.

\section{Introduction}

Apthous word is derived from the greek word aptha meaning "eruption" or "ulcer". Recurrent is the word added to name because of the nature of disease, occurring repeatedly in oral cavity at intervals. The etiology behind this disease is still unclear. Cell mediated immune response plays pivotal role in immunopathogenesis of apthous ulcer. ${ }^{1}$ There are at least 4 episodes of the disease per year. ${ }^{2}$ Prevalence is found to be higher in developed countries irrespective of age, race or geographic distribution. ${ }^{3}$

Sometimes it is related to systemic diseases like Crohn's disease and Behcet's disease, adversely influencing the quality of life of patients. ${ }^{4}$ Certain HLA findings in some patients strengthens role of genetic predisposition. ${ }^{5}$ Some patients report of prodromal burning sensation $2 \mathrm{hrs}$ to 2 days before the appearance of ulcer. ${ }^{6}$ Some predisposing factors are associated with RAS like trauma, vitamin deficiencies, stress, hormonal influences, immunologic parameters and microbial load. ${ }^{6,7}$

Initiation of cascade of inflammatory cytokines against oral mucosa triggerred by predisposing factors results in activation of T-lymphocytes and leukocyte chemotaxis. ${ }^{8}$ Production of cytokines like interferonalpha (INF- $\alpha$ ), interleukin-2, interleukin-12 and tumor necrosis factor-alpha (TNF- $\alpha$ ) from T-helper cells further contributes to the immune response. Some evidences of presence of auto-antibodies against oral mucosa are also found. ${ }^{9}$

\section{Current trends in management of RAS}

Clinical appearance of RAS is as single or multiple painful shallow round ulcers with pseudomembranous centre and erythematous margin. RAS has 3 subtypes; recurrent apthus major, minor and herpetiform. It mostly involves non keratinizing oral mucosa like buccal mucosa, labial mucosa and tongue. ${ }^{1,6}$ Till today it is difficult to catch whether a similar pathogenesis exists between RAS associated with other systemic disease and RAS unassociated with any systemic disease. ${ }^{10} \mathrm{~A}$ study by Ozyurt $\mathrm{K}$ et al., reveals that the serum interferon gamma, alpha-enolase levels, interleukin-1, interleukin-13, interleukin-18 were found to be in increased concentration in patients with Behcet's disease as well as RAS in comparison to healthy controls. ${ }^{10,11}$ There is no specific diagnostic test. The main basis of diagnosis is a meticulous patient history and gross clinical examination. Family history also plays a vital role. While examining the patient we must give concern to the size, number, location and frequency of ulcers. To have an idea about any underlying systemic cause we can run certain tests like estimation of full blood count, hemoglobin, C-reactive protein, erythrocyte sedimentation rate, vitamin $\mathrm{B} 12$ level, anti-endomysial and anti-gliadin autoantibodies. ${ }^{12}$

Our treatment must aim at reducing the duration and frequency of ulcers to improve the level of well being for the patient. Different patient respond differently to the various treatment regimens. Therapeutic approach may be topical or systemic as per the severity of disease. Several trials are undertaken to determine the best treatment approach for RAS. Antibiotic mouthrise are prescribed in mild initial cases. Chlorhexidine $0.2 \%$ mouth rinse or $1 \%$ gel formulation is known to reduce the duration and severity of disease. ${ }^{13} 5 \mathrm{ml}$ of minocycline, $0.2 \%$ mouthrinse in aqueous solution when rinsed 6 hourly provided early relief from RAS. ${ }^{14}$

Other topical treatments include application of dexamethasone ointment $(5 \mathrm{mg})$ on ulcers 3 times a day post meal for 5 days accelerated healing process ${ }^{15}$. Adhesive pellicles $(2 \mathrm{mg})$ of amelexanox or $5 \%$ paste formulation when applied 8 hourly, reduced pain intensity and size of ulcers. ${ }^{16,17}$ Reduction in pain was noted from day 1 after chemical cauterization of ulcer with siver nitrate pencil (1-2\%). ${ }^{18,19}$ We all know LASERS are paving their way as latest diagnostic and treatment modality. As far as RAS treatment is concerned $\mathrm{Nd}$ :YAG laser and $\mathrm{CO} 2$ laser treatment 
presented with immediate relief. ${ }^{20,21}$ Topical treatment modalities mentioned above have been proved to be effective in minor form of disease. But RAS with more recurring episodes and higher severity may need systemic therapy. Vitamin B supplementation accelerates the healing process. Systemic medications includes various drug regimens. Thalidomide $100 \mathrm{mg}$ oral when given daily for 15 days led to complete remission of RAS. ${ }^{22}$ But it is contraindicated in pregnancy and bears numerous side effects like headache, xerostomia, constipation. Colchicine $0.5 \mathrm{mg}$ daily oral dose for 3 months helped in reduction in number of ulcers and intensity of associated pain. ${ }^{23} 400$ $\mathrm{mg}$ of pentoxyfylline taken orally 3 times a day causes reduction in size of ulcer. ${ }^{24}$ Another drug in this row is clofazimine. When it was given at a dose of $100 \mathrm{mg}$ orally on alternate days, increased disease free intervals..$^{25}$ But clofazimine has certain cutaneous side effects. ${ }^{26}$

Systemic corticosteroids are well accepted treatment modalities in RAS major cases. $25 \mathrm{mg}$ daily administration of predinisone for 15 days followed by gradually tapered maintenance dose over next 45 days resulted in rapid healing along with decreased frequency of ulcers. ${ }^{27}$ Systemic administration of corticosteroids have a series of adverse reactions on body which must be kept in concern. Montelukast $10 \mathrm{mg} /$ day when given for 1 month and alternate day for next 30 days resulted in resolution of ulcers. ${ }^{27}$ Dapsone $100 \mathrm{mg}$ daily orally is also a treatment of choice. ${ }^{28} \mathrm{Zinc}$ sulfate $150 \mathrm{mg}$ daily oral dose for 12 weeks reduced the number and size of ulcers without any side-effect. ${ }^{29}$ Subantimicrobial dose of doxycycline (20mg) BD increased disease free periods. ${ }^{30}$ Rebamipide $100 \mathrm{mg}$ thrice in a day orally for 7-14 days caused reduction in number of ulcers and pain intensity. ${ }^{31}$ A randomized controlled trial by Volkov I et al revealed that a daily dose of vitamin B12 (1000 mcg) sublingually for 6 months decreased pain intensity and number of ulcers in RAS. ${ }^{32}$ Levamisole $150 \mathrm{mg} /$ day oral when given on 3 consecutive days every fortnight also gave positive treatment outcomes. ${ }^{33}$

\section{Novel therapeutic regimens}

Biologic agents are the latest trends in treatment of apthus ulcers. They block certain immunologic or pathophysiologic pathways of disease. They have targeted approach. Either they are immunosuppressive or anti-inflammatory in action ${ }^{34}$. Some names in this queue are etanercept, adalimumab, infliximab and IFNgamma.

Structurally, etanercept is a dimeric fusion protein comprising the extracellular portion of human TNF receptor (p75) coupled to the $\mathrm{Fc}$ fragment of human IgG. It is a recombinant TNF soluble receptor. It competitively inhibits the binding of TNF to TNF receptors thereby preventing TNF-mediated cell responses $^{35}$. It is given subcutaneously, at a dose of
$25 \mathrm{mg}$ two times a week ${ }^{36}$. It can be self administered by the patient. Studies suggest significant improvement in refractory cases as well as complete remission in some. ${ }^{35-38}$

A murine monoclonal antibody named infliximab acts against TNF-a. Infliximab when administered in a dose of $3-5 \mathrm{mg} / \mathrm{kg}$ intravenously every 2-6 weeks showed early healing and complete remission within 710 days in old RAS cases resistant to other treatment modalities. ${ }^{39-44}$ Adalimumab is a human monoclonal antibody. It binds to TNF- $\alpha$ resulting in inhibition of the activity of TNF- $\alpha$. It achieves higher affinity as compared to infliximab and etanernept. ${ }^{45}$ It has an advantage of having fewer side effects. Complete resolution or remission was found in several study cases of RAS with associated systemic dirsease. ${ }^{45-49}$ INF- $\alpha$ plays vital role in immune response. It helps in clearance of all foreign antigens and maintaining, immunological memory. Treatment with a low dose of INF- $\alpha$ causes de-acceleration of delayed-type hypersensitivity. ${ }^{50} \quad$ Topical $^{51}{ }^{51}$ oral $^{52,53}$ and subcutaneous $^{54,56}$ INF- $\alpha$ therapy diminished oral aphthous lesions.

\section{Conclusion}

Taking a thorough patient history and performing meticulous oral examination are key to sound diagnosis and treatment planning of recurrent apthous stomatitis. There is a strong need to rule out whether RAS is associated with any underlying systemic disease that need to be managed. Elimination of predisposing factors is mandatory for successful treatment. More studies need to be conducted to find a definite treatment protocol for RAS. There are several treatment options to which different patient responds differently. Biologic agents are recent trends that have been used to treat apthous ulcer as well as they are a ray of hope for the old refractory cases of RAS.

\section{References}

1. Beguerie JR, Sabas M. Recurrent aphthous stomatitis: An update on etiopathogenia and treatment. $J$ Dermatol Nurses Assoc 2015;7(1):8-12.

2. Vaillant L, Samimi M. Aphthous ulcers and oral ulcerations Presse Med (Paris, France: 1983). 2016;45(2):215-26.

3. Natah SS, Konttinen YT, Enattah NS, Ashammakhi N, Sharkey KA, Häyrinen-Immonen R. Recurrent aphthous ulcers today: A review of the growing knowledge. Int J Oral Maxillofac Surg 2004;33(3):221-34.

4. Ryu HJ, Seo MR, Choi HJ, Baek HJ. Infliximab for refractory oral ulcers. Am J Otolaryngol 2014;35(5):664-8.

5. Jurge S, Kuffer R, Scully C, Porter SR. Number VI recurrent aphthous stomatitis. Oral Dis 2006;12(1):121.

6. Akintoye SO, Greenberg MS. Recurrent aphthous stomatitis. Dental Clinics North Am 2014;58(2):28197. 
7. Preeti L, Magesh KT, Rajkumar K, Karthik R. Recurrent aphthous stomatitis. JOMFP 2011;15(3):252-6.

8. lebioda Z, Szponar E, Kowalska A. Etiopathogenesis of recurrent aphthous stomatitis and the role of immunologic aspects: Literature review. Archivum Immunologiae et al. Therapiae Experimentalis. 2014;62(3):205-15

9. Albanidou-Farmaki E, Markopoulos AK, Kalogerakou $\mathrm{F}$, Antoniades DZ. Detection, enumeration and characterization of $\mathrm{T}$ helper cells secreting type 1 and type 2 cytokines in patients with recurrent aphthous stomatitis. Tohoku J Exp Med 2007;212(2):101-5.

10. Taylor J, Glenny AM, Walsh T, Brocklehurst P, Riley $\mathrm{P}$, Gorodkin R, et al.Interventions for the management of oral ulcers in Behçet's disease. Cochrane Database Syst Rev 2014;9:CD011018.

11. Ozyurt K, Çelik A, Sayarlıoglu M, Colgecen E, Incı R, Karakas T, et al. Serum Th1, Th2 and Th17 cytokine profiles and alpha-enolase levels in recurrent aphthous stomatitis. J Oral Pathol Med 2014;43(9):691-5.

12. Tarakji B, Gazal G, Al-Maweri SA, Azzeghaiby SN, Alaizari N. Guideline for the diagnosis and treatment of recurrent aphthous stomatitis for dental practitioners. Journal of International Oral Health: JIOH 2015;7(5):74-80.

13. Altenburg A, Abdel-Naser MB, Seeber H, Abdallah M, Zouboulis CC. Practical aspects of management of recurrent aphthous stomatitis. J Eur Acad Dermatol Venereol 2007;21(8):1019-26.

14. Gorsky M, Epstein JB, Rabenstein S, Elishoov H, Yarom N. Topical minocycline and tetracycline rinses in treatment of recurrent aphthous stomatitis: a randomized cross-over study. Dermatol Online J 2007;13(2):1.

15. Keenan AV. Promising results for dexamethasome ointment for treatment of recurrent aphthae. Evid Based Dent 2012;13(3):75.

16. Meng W, Dong Y, Liu J, Wang Z, Zhong X, Chen R, et al. A clinical evaluation of amlexanox oral adhesive pellicles in the treatment of recurrent aphthous stomatitis and comparison with amlexanox oral tablets: a randomized, placebo controlled, blinded, multicenter clinical trial. Trials. 2009;10(1):30.

17. Fernandes R, Tuckey T, Lam P, Allidina S, Sharifi S, Nia D. The best treatment for aphthous ulcers: an evidence based study of the literature. Available at: https://www.dentistry.utoronto.ca/system/files/aphthou sulcers.pdf. Accessed June 14, 2016.

18. Altenburg A, El-Haj N, Micheli C, Puttkammer M, Abdel-Naser MB, Zouboulis CC. The treatment of chronic recurrent oral aphthous ulcers. Deutsches Ärzteblatt Int. 2014;111(40):665-73. 2014;36:5.

19. Alidaee MR, Taheri A, Mansoori P, Ghodsi SZ. Silver nitrate cautery in aphthous stomatitis: a randomized controlled trial. Br J Dermatol 2005;153(3):521-5.

20. Tezel A, Kara C, Balkaya V, Orbak R. An evaluation of different treatments for recurrent aphthous stomatitis and patient perceptions: Nd: YAG laser versus medication. Photomed Laser Surg 2009;27(1):101-6.

21. Prasad S, Pai A. Assessment of immediate pain relief with laser treatment in recurrent aphthous stomatitis. Oral Surg Oral Med Oral Pathol Oral Radiol 2013;116(2):189-93.

22. Mimura MA, Hirota SK, Sugaya NN, Sanches Jr JA, Migliari DA. Systemic treatment in severe cases of recurrent aphthous stomatitis: an open trial. Clinics (Sao Paulo, Brazil). 2009;64(3):193-8.
23. Pakfetrat A, Mansourian A, Momen-Heravi F, Delavarian Z, Momen-Beitollahi J, Khalizadeh O et al. Comparision of colchicines versus prednisolone in recurrent aphthous stomatitis:A double blind randomized clinical trial. Clin Invest Med 2010;33(3):189-95.

24. Thornhill MH, Baccaglini L, Theaker E, Pemberton $\mathrm{MN}$. A randomized,double blind, placebo-controlled trial of pentoxifylline for the treatment of recurrent aphthous stomatitis. Arch Dermatol 2007;143(4):46370.

25. De Abreu MA, Hirata CH, Pimentel DR, Weckx LL. Treatment of recurrent aphthous stomatitis with clofazimine. Oral Surg Oral Med Oral Pathol Oral Radiol Endod 2009;108(5):714-21.

26. Brocklehurst P, Tickle M, Glenny AM, Lewis MA, Pemberton MN, Taylor J, et al. Systemic interventions for recurrent aphthous stomatitis (mouth ulcers). Cochrane Database Syst Rev 2012;9:CD005411.

27. Femiano F, Buonaiuto C, Gombos F, Lanza A, Cirillo N. Pilot study on recurrent aphthous stomatitis (RAS): a randomized placebo-controlled trial for the comparative therapeutic effects of systemic prednisone and systemic montelukast in subjects unresponsive to topical therapy. Oral Surg Oral Med Oral Pathol Oral Radiol Endod 2010;109(3):402-7.

28. Sharquie KE, Najim RA, Abu-Raghif AR. Dapsone in Behçet's disease: a doubleblind, placebo-controlled, cross-over study. J Dermatol 2002;29(5):267-79.

29. .Sharquie KE, Najim RA, Al-Hayani RK, Al-Nuaimy AA, Maroof DM. The therapeutic and prophylactic role of oral zinc sulfate in management of recurrent aphthous stomatitis (RAS) in comparison with dapsone. Saudi Med J 2008;29(5):734-38.

30. Preshaw PM, Grainger P, Bradshaw MH, Mohammad AR, Powala CV, Nolan A. Subantimicrobial dose doxycycline in the treatment of recurrent oral aphthous ulceration: A pilot study. J Oral Pathol Med 2007;36(4):236-40.

31. Kudur MH, Hulmani M. Rebamipide: A novel agent in the treatment of recurrent aphthous ulcer and Behcet's syndrome. Ind J Dermatol 2013;58(5):352.

32. Volkov I, Rudoy I, Freud T, Sardal G, Naimer S, Peleg $\mathrm{R}$, et al. Effectiveness of vitamin B12 in treating recurrent aphthous stomatitis: a randomized, doubleblind, placebo-controlled trial. J Am Board Fam Med 2009;22(1):9-16.

33. Meyer JD, Degraeve M, Clarysse J, Loose FD, Peremans W. Levamisole in apthous stomatitis: Evaluation of 3 regimens.

34. Georgakopoulou EA, Andreadis D, Arvanitidis E, Loumou P. Biologic agents and oral diseases--an update on clinical applications. Acta Dermatovenerol Croat 2013;21(1):24-34

35. Robinson ND, Guitart J. Recalcitrant, recurrent aphthous stomatitis treated with etanercept. Arch Dermatol 2003;139:1259-62.

36. Altenburg A, Zouboulis CC. Current concepts in the treatment of recurrent aphthous stomatitis. Skin Therapy Lett 2008:13(7):1-4.

37. Hasan A, Patel H, Saleh H, Youngberg G, Litchfield J, Krishnaswamy G. Remission of severe aphthous stomatitis of celiac disease with etanercept. Clin $\mathrm{Mol}$ Allergy 2013;11:6.

38. Gonzalez-Lopez MA, Blanco R, Garcia-Ibarbia C, Gonzalez-Vela CM, Gonzalez-Gay MA. Etanerceptinduced hypertriglyceridemia during the treatment of 
recurrent aphthous stomatitis. Ind J Dermatol Venereol Leprol 2013;79(3):432-33.

39. Ting PT, Koo J. Use of etanercept in human immunodeficiency virus (HIV) and acquired immunodeficiency syndrome (AIDS) patients. Int $J$ Dermatol 2006;45(6):689-92.

40. Travis SP, Czajkowski M, McGovern DP, Watson RG, Bell AL. Treatment of intestinal Behçet's syndrome with chimeric tumour necrosis factor $\alpha$ antibody. Gut 2001;49(5):725-28.

41. Almoznino G, Ben-Chetrit E. Infliximab for the treatment of resistant oral ulcers in Behcet's disease: a case report and review of the literature. Clin Exp Rheumatol 2007;25(4 Suppl 45):S99-102.

42. Robertson LP, Hickling P. Treatment of recalcitrant orogenital ulceration of Behçet's syndrome with infliximab. Rheumatology (Oxford). 2001;40(4):473-4.

43. Kaufman I, Caspi D, Yeshurun D, Dotan I, Yaron M, Elkayam O. The effect of infliximab on extraintestinal manifestations of Crohn's disease. Rheumatol Int 2005;25(6):406-10.

44. Bañeros-Rojas P, Berrozpe-Villabona C, PerazaNieves JE, Díaz-Valle D. Early treatment with infliximab in bilateral occlusive vasculitis as a presenting manifestation of Behçet'disease. Arch Soc Esp Oftalmol 2015;90(6):285-8.

45. Kaji M, Kishi T, Miyamae T, Nagata S, Yamanaka H, Fujikawa S. Efficacy of adalimumab in a girl with refractory intestinal Behcet's disease. Case Reports in Rheumatol 2015;2015:716138.

46. Ueda A, Takeno M, Ishigatsubo Y. Adalimumab in the management of Behçet's disease. Therap Clin Risk Mgmt 2015;11:611.

47. Tanida S, Inoue N, Kobayashi K, Naganuma M, Hirai F, lizuka B, et al. Adalimumab for the treatment of Japanese patients with intestinal Behçet's disease. Clin Gastroenterol Hepatol. 2015;13(5):940-8.e3.

48. Perra D, Alba MA, Callejas JL, Mesquida M, RíosFernández R, Adán A, et al. Adalimumab for the treatment of Behçet's disease: experience in 19 patients. Rheumatology (Oxford). 2012;51(10):182531.

49. Vujevich J, Zirwas M. Treatment of severe, recalcitrant, major aphthous stomatitis with adalimumab. Cutis 2005;76(2):129-32.

50. Brassard DL, Grace MJ, Bordens RW. Interferon- $\alpha$ as an immunotherapeutic protein. J Leukoc Biol 2002;71(4):565-81.

51. Hamuryudan V, Yurdakul S, Serdaroglu S, Tüzün Y, Rosenkaimer F, Yazici H. Topical alpha interferon in the treatment of oral ulcers in Behcet's syndrome: a preliminary report. Clin Exp Rheumatol 1990;8(1):514.

52. Hutchinson VA, Angenend JL, Mok WL, Cummins JM, Richards AB. Chronic recurrent aphthous stomatitis: oral treatment with low-dose interferon alpha. Mol Biother 1990;2(3):160-4.

53. Kılıç H, Zeytin HE, Korkmaz C, Mat C, Gül A, Coşan $\mathrm{F}$, et al. Low-dose natural human interferon- $\alpha$ lozenges in the treatment of Behçet's syndrome. Rheumatol (Oxford). 2009;48(11):1388-91.

54. Alpsoy E, Durusoy C, Yilmaz E, Ozgurel Y, Ermis O, Yazar S, et al. Interferon alfa-2a in the treatment of Behcet disease: a randomized placebo-controlled and double-blind study. Arch Dermatol 2002;138(4):46771.

55. Karagiannidis I, Zouboulis CC. Systemic Adamantiades-Behcet's disease: adverse effects of an otherwise successful therapy with interferon- $\alpha$ - 2 a. Dtsch Med Wochenschr. 2015;140(2):112-3.

56. Kötter I, Vonthein R, Zierhut M, Eckstein AK, Ness T, Günaydin I, et al. Differential efficacy of human recombinant interferon-alpha2a on ocular and extraocular manifestations of Behçet disease: results of an open 4-center trial. Semin Arthritis Rheum 2004;33(5):311-9. 